DOI: $10.22616 /$ REEP.2020.008

\title{
Professional Motives as a Leading Factor of last Year University Students' Learning Motivation
}

\author{
Jelena Jermolajeva ${ }^{1}$ Dr.paed.; Svetlana Silchenkova ${ }^{2} \mathrm{PhD}$; Larissa Turusheva ${ }^{3}$ Dr.paed. \\ EKA University of Applied Sciences, Latvia ${ }^{1,3}$ \\ Smolensk State University, Russia ${ }^{2}$ \\ jjerm@latnet.lv¹, sil-sv@mail.ru², larisa.turuseva@eka.edu.lv³
}

\begin{abstract}
Much pedagogical research is focused on students' academic performance. However, students' motivation aspect is of no less importance; it allows academic staff to look at the results of their work with students from another point of view, and reflect on possible changes in teaching. In this article the learning motivation of last year students is studied. The aim of the study is to analyse learning motivation of last year students at the universities of Riga (EKA University of Applied Sciences) and Smolensk (Smolensk State University), identify and compare the prevailing groups of motives. For data collection, a survey was used; data processing methods were descriptive statistics, analysis of statistical indicators, and Spearman correlation analysis. The international survey was carried out in December 2018 (Smolensk) and June 2019 (Riga), with participation of 101 student (56+45, correspondingly). The analysis of the data shows that in both samples, the group of the professional motives plays the leading role in the learning motivation of students. The strongest professional motive is "I want to become a specialist". The data reveal that the learning motivation of the Latvian participants is slightly higher, than that of the Russian participants. The study is the first step in the Latvian-Russian research project on students' motivation at higher education institutions. Its results can be used by university teachers and study programme directors for improving the management of education and raising the quality of the pedagogical process.
\end{abstract}

Keywords: university education, learning motivation, professional motives of learning.

\section{Introduction}

In a modern higher school the student-centred paradigm is recognised as one of the main principles of the effectiveness of the educational process. This explains the increased interest of researchers in the personality of the student, in particular, studying the variety of academic motivation of students (Zhanguzhinova et al., 2018; Purdie, Hattie, 2002; Illeris, 2009). Working with students, there is always a situation when some students have better academic outcomes, while others do not have very good results. Then a question arises, what makes them differ? It is obvious that young people come to the university to study, to develop their professional and academic skills, to receive a diploma at least. Though, it appears that their motivation is different, which influences their results of learning.

Many authors indicate the importance of academic motivation for the outcome of learning process (Boekaerts, 2010; Lamb, 2017), argue the necessity of improving motivation. Studying motivation is necessary for understanding the ways of promoting its quality (Safronova, Klyukina, 2019; Fleisher, 2009).

Motivation theories appeared long ago, as scholars paid attention on the importance of it for the performance of people at work, as well as of students in the studying process. One of the most famous and widely used theories is that of A.H. Maslow's Need Hierarchy Theory, where he classified human needs in a hierarchical order from the lowest to the highest: a) Physiological, basic needs; b) Safety needs; c) Love and belongingness needs (social needs); d) Esteem needs; e) Self-actualisation needs; as he was sure that a human can be motivated with some need only when the previous, lower needs are achieved (Maslow, 1943, 375). A.H. Maslow's theory was accepted as a revolutionary one, because it was easy to explain a human motivation with such a simple hierarchy. Though, looking deeper into the human nature, as well as taking into account the cases from history, it can be proved that even hungry people (as an example) can dream about high ideals; at war heroes saved the life of kids or other people, sacrificing themselves. Thus, it seems that "a person may be motivated by higher growth needs at the same time as lower level deficiency needs" (McLeod, 2018). 
Psychologists nowadays see motivation "as a pluralistic behaviour, whereby needs can operate on many levels simultaneously" (McLeod, 2018), or, as A.H. Maslow himself formulated developing his earlier theory: "any behaviour tends to be determined by several or all of the basic needs simultaneously rather than by only one of them" (Maslow, 1954).

Analysing different theories on motivation, D.C. McClelland's Need Theory (McClelland, 1961) looks more appropriate and useful for deeper understanding motivation of learners, as he was sure that needs are acquired (learned) by the experience. Based on three needs (achievement, power and affiliation), it proves that people having a particular need behave differently from those who do not have any. According to D.C. McClelland's, a need for achievement "is a behaviour directed toward competition with a standard of excellence" (McClelland, 1961). D.C. McClelland found that people with a high need for achievement perform better than those with a moderate or low need for achievement, and noted regional/national/cultural differences in achievement motivation, which in current research may partly explain different results of Smolensk and Riga students.

Research on motivation immediately addresses the separate issue of the motivation diagnostics, that is, qualitative or/and quantitative assessment of motivation, its elements and their systemic unity. Priorities hierarchy, conscious and unconscious components, stabile and changing parts, situational peculiarities, dynamics of motivation can be detected using either questionnaires based on different systems of empirical indicators and criteria, or psychosemantic, projective and semi-projective tools (Strizhova, Gusev, 2013; Van Roy, Zaman, 2019). Since the academic motivation of last year university students is the subject of the research, the emphasis in this study is on conscious motivation. Last year students are almost professionals with well-developed self-reflection, therefore the diagnostics of their conscious motivation is of the special interest to teachers (whereas, for example, in the case of children and teenagers much more attention should be paid to unconscious motivation). Usually, focus on students' academic outcome is predominant; however, motivation diagnostics data allow academic staff to look at the results of several years of their work with students from another point of view, and reflect on possible changes in their teaching.

The aim of the study is to analyse learning motivation of last year students at the universities of Riga (EKA University of Applied Studies) and Smolensk (Smolensk State University), identify and compare the prevailing groups of motives.

\section{Methodology}

The method of data collection is a survey; data processing methods are a table method, descriptive statistics, an analysis of statistical indicators, and Spearman correlation analysis. Studying conscious motivation, the method of direct survey is often used, in which a questionnaire contains a certain number of motives (closed-type items) for evaluating by respondents. (Guiffrida et al., 2013; Nadler, Lawler III, 2007). For this study, a motivation diagnostics technique was required, which makes it possible to identify the main groups of learning motives, compare them with each other and highlight the strongest group. The most appropriate appeared to be the N.Ts. Badmayeva technique "Diagnostics of educational motivation of students" (Badmayeva, 2004). This technique is well-balanced, regarding the completeness of the presented groups of motives and, at the same time, a relatively small number of these groups (seven); it allows one to determine the level of motivation for learning and the prevailing motives.

The learning motives are divided into the following groups.

- Scale 1: communication motives that show how motivated students are to communicate with their fellow students and in the future with colleagues.

- Scale 2: motives of avoidance, demonstrating how the respondents are forced to learn in order not to lag behind their fellow students and avoid condemnation.

- Scale 3: motives of prestige, showing the desire to be the best in everything.

- Scale 4: professional motives that demonstrate a focus on acquiring a profession.

- Scale 5: motives of creative self-realisation, which show how much the interviewers want to be realised as a creative personality.

- Scale 6: educational and cognitive motives that show the desire to gain knowledge.

- Scale 7: social motives that demonstrate the desire to be successful in the society. 
The questionnaire has a total of 34 statements (items), which are offered for respondents' evaluation in a 5-point system: 1 point means the minimum value of the motive, 5 points - the maximum. Each scale includes several items (from 2 to 7); the scale rate is calculated as the average of the indicators of the statements related to the scale. Items of the questionnaire are not arranged by scales, i.e. statements of the same scale do not follow each other, but are scattered throughout the questionnaire.

Participation of two national groups of respondents allows researchers to look at the subject of the study more stereoscopically. The international survey was carried out in December 2018 (Smolensk) and June 2019 (Riga). The study involved 101 last year university students of graduation in 2019. They represented two universities of Latvia and Russia: EKA University of Applied Sciences (EKA) - 45 students, and Smolensk State University (SmolSU) - 56 students. The graduates of SmolSU were trained in economics and management; the graduates of EKA, in addition to the named areas, - in law and translation. The average age of the respondents in Riga is 25 years, the maximum age is 31 years; the average age of respondents in Smolensk is 22 years, the maximum age is 23 years. The number of female students in the Riga and Smolensk samples exceeds the number of males: in Riga sample the number of females is 35 , or $77.8 \%$, in Smolensk sample - 33, or $58.9 \%$.

The questionnaire was tested by Cronbach's Alfa method. The corresponding coefficient is 0.985 for Riga data and 0.947 for Smolensk. The high value of the coefficient shows a high internal coherence of characteristics describing the samples and testifies the reliability of the technique.

\section{Results and Discussions}

For each of the two national samples, the following descriptive statistics was calculated for 34 statements and seven scales: mean value, mode, dispersion, and coefficient of variation $(\mathrm{CoV})$, showing the fluctuation of answers. Table 1 presents the indicators of the seven motivation scales for EKA and SmolSU students.

Table 1

Learning motivation of Riga and Smolensk last year students

\begin{tabular}{lcccccccc}
\hline \multicolumn{1}{c}{$\begin{array}{c}\text { Scale of learning } \\
\text { motivation }\end{array}$} & \multicolumn{4}{c}{ MKA } & \multicolumn{5}{c}{ SmolSU } \\
\hline $\begin{array}{l}\text { Communicative } \\
\text { motives }\end{array}$ & 3.32 & 4 & 1.01 & 30.31 & 3.02 & 3 & 1.56 & 41.27 \\
Motives for avoidance & 2.06 & 1 & 1.48 & 59.02 & 2.14 & 1 & 1.38 & 54.99 \\
Motives for prestige & 2.62 & 3 & 0.92 & 36.52 & 2.43 & 1 & 1.53 & 50.85 \\
Professional motives & $\mathbf{4 . 0 7}$ & $\mathbf{4}$ & $\mathbf{0 . 5 4}$ & $\mathbf{1 8 . 0 3}$ & $\mathbf{3 . 4 4}$ & $\mathbf{4}$ & $\mathbf{1 . 5 0}$ & $\mathbf{3 5 . 5 7}$ \\
$\begin{array}{l}\text { Motives for creative } \\
\text { self-realisation }\end{array}$ & 3.3 & 3 & 0.68 & 25.07 & 2.53 & 3 & 1.30 & 45.06 \\
$\begin{array}{l}\text { Educational motives } \\
\text { Social motives }\end{array}$ & 3.27 & 3 & 0.96 & 29.89 & 2.73 & 3 & 1.58 & 46.05 \\
$\begin{array}{l}\text { Mean for all } \\
\text { statements }\end{array}$ & 2.82 & 3 & 0.79 & 31.51 & 3.12 & 3 & 1.88 & 43.98 \\
\hline
\end{tabular}

The mean value of all statements of the questionnaire is 3.08 in Riga sample and 2.81 in Smolensk sample; the difference is 0.27 . The most often score in the questionnaire is 3 in both samples. These results show that in general, Latvian and Russian last year university students have a relatively good educational motivation. However, a high discrepancy of respondents' answers, especially in the Smolensk sample, indicates a great diversity of personal approaches, dependent on respondents' personal circumstances and hierarchies of values. In the data of SmolSU sample, CoV for all motivation scales exceeds $33 \%$, which means that the average values are not reliable enough to make strong generalizations based on them. In the Latvian sample, only 2 of 7 scales exceed $33 \%$. Nevertheless, certain conclusions can still be made by a closer examination of the data.

As seen from Table 1, in both samples the highest rating is obtained for the scale of the professional motives. In Riga sample, the average for professional motives is 4.07, in Smolensk - 3.44. In both universities, at the same time, this scale has also a minimum CoV: $18.03 \%$ and $35.57 \%$, 
correspondingly. Since professional motivation is the most important for graduates, and students have shown the highest score on it and the greatest unanimity, a closer look at this block is necessary. Professional motivation scale consists of 6 statements. The formulations of the motives and the main descriptive statistics of the data obtained are shown in Table 2.

Table 2

Professional motivation of last year students in Riga and Smolensk

\begin{tabular}{|c|c|c|c|c|c|}
\hline Scale "Professional motives" & University & Mean & Mode & Dispersion & $\begin{array}{l}\text { CoV } \\
(\%)\end{array}$ \\
\hline \multirow{2}{*}{ 1. I study because I like the chosen profession } & EKA & 4.13 & 4 & 0.30 & 13.25 \\
\hline & SmolsU & 3.43 & 4 & 1.27 & 32.84 \\
\hline \multirow{2}{*}{$\begin{array}{l}\text { 2. To ensure the success of future professional } \\
\text { activities }\end{array}$} & EKA & 4.20 & 5 & 0.66 & 19.40 \\
\hline & SmolsU & 3.46 & 4 & 1.38 & 33.92 \\
\hline \multirow{2}{*}{ 3. I want to become a specialist } & EKA & 4.29 & 5 & 0.57 & 17.66 \\
\hline & SmolsU & 4.00 & 5 & 1.13 & 26.54 \\
\hline \multirow{2}{*}{$\begin{array}{l}\text { 4. To propose a solution to the most pressing } \\
\text { problems related to the future profession }\end{array}$} & EKA & 3.76 & 4 & 0.46 & 18.09 \\
\hline & SmolsU & 2.80 & 3 & 1.51 & 43.77 \\
\hline \multirow{2}{*}{$\begin{array}{l}\text { 5. I want to make full use of my skills, abilities } \\
\text { and inclinations for my chosen profession }\end{array}$} & EKA & 3.98 & 4 & 0.48 & 17.36 \\
\hline & SmolsU & 3.25 & 4 & 1.57 & 38.59 \\
\hline \multirow{2}{*}{ 6. To become a highly qualified professional } & EKA & 4.04 & 4 & 0.63 & 19.69 \\
\hline & SmolsU & 3.71 & 4 & 1.44 & 32.35 \\
\hline \multirow{2}{*}{ Mean for the scale } & EKA & 4.07 & 4 & 0.54 & 18.03 \\
\hline & SmolsU & 3.44 & 4 & 1.50 & 35.57 \\
\hline
\end{tabular}

In both samples, the $3^{\text {rd }}$ motive "I want to become a specialist" takes the first place as the most important motive for students' learning not only among the statements of this scale, but throughout whole questionnaire. In the sample of Riga, the mean rate of this motive is 4.29 points, Smolensk indicator is 4.00 (at this item there is a minimum difference of results between the samples). Most students in Riga and Smolensk rate the $3^{\text {rd }}$ statement with 5-points (mode 5). In both samples, $\mathrm{CoV}$ of answers to this statement is less than $33 \%$, which testifies that the mean and mode can be considered typical and reliable.

The $6^{\text {th }}$ statement ("To become a highly qualified professional") of this block somewhat bewilders students; some of them are thinking it is enough to become a specialist, being highly qualified is optional. The mean for this statement is 4.04 for Riga last year students and 3.71 for Smolensk ones; although the rates are relatively high, they are 6-7\% lower than the scores for the $3^{\text {rd }}$ statement. This result can be interpreted in different ways: perhaps some students are afraid of professional responsibility; possibly, they are unsure in the choice of future profession, or do not want to pay much importance to their future work.

As can be seen in Table 2, the students of Riga give higher scores than Smolensk ones to all the statements of the scale. Compared to SmolSU, EKA students find the $2^{\text {nd }}$ motive ("To ensure the success of future professional activities") more important: mean rates are 4.20 vs. 3.46. The same, with a slight decrease in ratings, is observed in the answers to the $5^{\text {th }}$ statement ("I want to make full use of my skills, abilities and inclinations for my chosen profession"): 3.98 vs. 3.25. It should be noted in addition that at these items $\mathrm{CoV}$ in Russian sample are too large: $33.92 \%$ and $38.59 \%$, whereas the discrepancy of Latvian answers here (as well as in all other items of the scale) does not exceed the critical limit of $33 \%$.

The scores given by the Smolensk students to the $1^{\text {st }}$ statement ("I study because I like the chosen profession") have been unexpected. Usually, young people choose a university study programme, because they like a future profession. However, there are $10 \mathrm{SmolSU}$ students (18\% of respondents), who rate this statement by 1-2 points. This explains the lower general motivation to learn observed in the Smolensk sample. All Riga students rated the $1^{\text {st }}$ statement above 2 points, even the number of "threes" is small -4 $(9 \%)$. This may indicate a more conscious choice of profession by young people in Riga, which is probably the result of a better organisation of professional orientation at Latvian schools.

In both samples, the lowest score is observed in the 4th statement ("To propose a solution to the most pressing problems related to the future profession"). The low score for this item suggests that the graduates do not really believe in themselves, do not hope (may be do not want) to become leading professionals and offer 
innovative approaches to problems, are not ready to research in the professional field. The Smolensk data show the highest discrepancy of answers in this item (inside the professional scale): $C o V=43.77 \%$. Despite the fact that the mode is 3 (which is, generally speaking, not such a low score), 22 Smolensk students (39.3\%) rated their motivation for this statement by 1 or 2 points; the mean value is 2.80 . The Latvian indicators are higher and more consistent: the mean is 3.76, mode is $4, \mathrm{CoV}=18.09 \%$. Among the professional motives, the highest difference between mean rates of the samples is observed at this item: 0.96 .

The analysis of the survey results requires an additional research. Preliminarily, several factors may be suggested responsible for the lag of the Latvian students' academic motivation behind the motivation of Russian graduates. The first possible reason is the above-mentioned effective professional orientation at Latvian schools. Probably, professional guidance at Russian schools should be strengthened, taking into account the Latvian experience in this field.

Secondly, the difference in age could affect how consciously the choice of profession was made and, accordingly, how much further learning is motivated. Separately in each sample, the Spearman rank correlation analysis did not reveal a statistically significant connection between students' age and their average motivation. However, the age difference between Russian and Latvian samples is quite large. The average and maximum age of the respondents are 25 and 31 years for EKA students, 22 and 23 for SmolSU graduates. Education at a Latvian school lasts a year longer than at a Russian one; in addition, it seems that Latvian teenagers more often than their peers in Russia do not immediately enter the college or university but go to work and take some time to think in what direction to develop their career. Besides, a younger age of Smolensk students and, accordingly, less conscious choice of profession may be explained (at least partly) by the system of the compulsory military service in Russia. If a young man does not want to join the army, he enters a university and gets postponement.

Thirdly, an atmosphere in the student group may influence the students' academic motivation. The authors plan to study the influence of the atmosphere in student team on the student's learning motivation at the next stage of the research project. Here it can be noted that the atmosphere in the group may affect students' learning motivation in different directions. For example, students with high socialising on campus, who place a high priority on meeting and interacting with peers, are sometimes less interested in successful learning compared with fellow students who are not so keen on such a pastime (Guiffrida et al., 2013). Perhaps this factor affected, to some extent, the learning motivation of Smolensk students, many of whom live on campus (whereas Riga students generally do not live in a student hostel).

\section{Conclusions}

- In general, EKA and SmolSU last year students have relatively good educational motivation. However, a high discrepancy of respondents' answers, especially in the Smolensk sample, indicates a great diversity of personal approaches dependent on respondents' personal circumstances and hierarchies of values.

- In both samples, the leading scale in the learning motivation of the last year students is the scale of the professional motives. Thus, the universities that participated in the research mostly fulfil their role in training of highly qualified professionals.

- Among the professional motives, the motive "I want to become a specialist" takes the first place as the most important motive for students' learning, not only among the statements of the professional scale, but throughout the questionnaire. Most students give it the highest score; their answers are well-agreed in both samples.

- In both samples, the least popular professional motive is the motive "I learn to propose a solution to the most pressing problems related to the future profession". In the Smolensk data there is a large proportion of low scores in this item, which indicates that the graduates do not really believe in themselves, do not hope (may be do not want) to become leading professionals and offer innovative approaches to problems, are not ready to research in the professional field.

- In general, the EKA students gave slightly higher scores to learning motives, than the SmolSU students did; the data of Riga students are also more consistent. This shows a higher learning motivation of the Latvian participants of the research, compared with the Russian participants. 
The detailed analysis requires an additional research; some considerations in this regard are made in the text of the article.

- The study is the first step in the Latvian-Russian research project on students' motivation at higher education institutions. University teachers and study programme directors can use its results for improving the management of education and raising the quality of the pedagogical process. Diagnostics data allow the academic staff to look at the results of several years of their work with students from a different point of view, and reflect on possible changes in their teaching.

\section{Bibliography}

1. Badmayeva N.T. (2004). Vliyanie motivacionnogo faktora na razvitie umstvennyx sposobnostej [The influence of motivational factor on the development of mental abilities]. UlanUde: Publishing Hous VSGTU. (in Russian)

2. Boekaerts M. (2010). The Crucial Role of Motivation and Emotion in Classroom Learning. In H. Dumont, D. Istance, F. Benavides (Eds.), The Nature of Learning: Using Research to Inspire Practice. OECD: Centre for Educational Research and Innovation, 91-111. doi: $10.1787 / 9789264086487-6$-en

3. Fleisher S. (2009). Book review: Motivation and Self-Regulated Learning: Theory, Research, and Applications. International Journal Scholarship of Teaching and Learning, 3(1), Article 37, 4-26.

4. Guiffrida D.A., Lynch M.F., Wall A.F., Abel D.S. (2013). Do Reasons for Attending College Affect Academic Outcomes? A Test of a Motivational Model From a Self-Determination Theory Perspective. Journal of College Student Development, 54(2), 121-139. doi: 10.1353/csd.2013.0019

5. Illeris K. (2009). A Comprehensive Understanding of Human Learning. In K. Illeris (Ed.), Contemporary Theories of Learning: Learning Theorists - in Their Own Words. London, New York: Routledge, 7-20.

6. Lamb M. (2017). The Motivational Dimension of Language Teaching. Language Teaching, 50(3), 301-346. doi: 10.1017/S0261444817000088

7. Maslow A.H. (1943). A theory of human motivation. Psychological Review, 50(4), 370-396. doi: $10.1037 / \mathrm{h} 0054346$

8. Maslow A.H. (1954). Motivation and personality. New York: Harper and Row Publishers, Inc. Retrieved from http://s-f-walker.org.uk/pubsebooks/pdfs/Motivation_and_Personality-Maslow.pdf

9. McClelland D.C. (1961). The Achieving Society. Princeton, New York: Van Nostrand.

10. McLeod S.A. (2018). Maslow's hierarchy of needs. Retrieved from https://www.simplypsychology.org/maslow.html

11. Nadler D.A., Lawler III E.E. (2007). Motivation: A Diagnostic Approach. In J.S. Osland, M.E. Turner, D.A. Kolb, I.M. Rubin (Eds.), The Organizational Behavior Reader ( ${ }^{\text {th }}$ ed.). Upper Saddle River: Pearson Prentice Hall, 171-180.

12. Purdie N., Hattie J. (2002). Assessing Students' Conceptions of Learning. Australian Journal of Educational \& Developmental Psychology, 2, 17-32. Retrieved from https://www.newcastle.edu.au/__data/assets/pdf_file/0017/100493/v2-purdie-hattie.pdf

13. Safronova V., Klyukina E. (2019). Some Aspects of Motivating Tertiary Students in Learning Oriental and European Languages. In V. Dislere (Ed.), The Proceedings of the International Scientific Conference Rural Environment. Education. Personality (REEP), 12. Jelgava: Latvia University of Life Sciences and Technologies, 158-164. doi: 10.22616/REEP.2019.020

14. Strizhova E., Gusev A. (2013). Motivational Task: Methodology and Method of Work Motivation Diagnostics. Procedia-Social and Behavioral Sciences, 86, 551-556. doi: 10.1016/j.sbspro.2013.08.612

15. Van Roy R., Zaman B. (2019). Unravelling the ambivalent motivational power of gamification: A basic psychological needs perspective. International Journal of Human-Computer Studies, 127 38-50. doi: 10.1016/j.ijhcs.2018.04.009

16. Zhanguzhinova M., Magauova A., Satova A., Mamanova A. (2018). The Study of Student's Motivation for Future Professional Activity. In V. Dislere (Ed.), The Proceedings of the International Scientific Conference Rural Environment. Education. Personality (REEP), 11. Jelgava: Latvia University of Life Sciences and Technologies, 162-169. doi: 10.22616/REEP.2018.019 